\title{
Sikap Masyarakat Terhadap Pengembangan Wisata Pantai Botutonuo Kabupaten Bone Bolango
}

\author{
Nurlayla latif ${ }^{1}$, Ummyssalam A.T.A Duludu ${ }^{2}$ \\ Pendidikan Luar Sekolah Fakultas Ilmu Pendidikan Universitas Negeri Gorontalo \\ nurlatif191@gmail.com ${ }^{1}$, ummyssalamduludu@ung.ac.id ${ }^{2}$
}

Received: 01 September 2021; $\quad$ Revised: 31 Desember 2021; $\quad$ Accepted: 31 Desember 2021

\begin{abstract}
The purpose of this study was to determine the attitude of the community towards the development of Botutonuo Beach Tourism, Bone Bolango Regency, Gorontalo Province. This type of research uses descriptive qualitative research, and data collection techniques use observation, interview, and documentation techniques. The results showed that the people's attitude towards the development of Botutonuo alley 1 beach tourism was quite good. This is based on the attitude of the community towards public facilities available on botutonuo beach tourism, such as lodging, food stalls, public toilets / toilets, prayer rooms, wooden huts, parking lots, and boat services. The availability of these facilities can be of particular value for the development of Botutonuo beach tourism. In addition, the public's attitude towards the cleanliness of tourist objects is known that the management always keeps the environment clean, by constantly cleaning the beach environment, lodging areas, wooden huts and providing trash bins around the beach area.However, there are also tourists who litter. There is still a tendency to littering the environment in Botutonuo beach.
\end{abstract}

Keywords: Community attitudes, tourism development, beach.

\section{ABSTRAK}

Tujuan penelitian ini untuk mengetahui Sikap Masyarakat Terhadap Pengembangan Wisata Pantai Botutonuo Kabupaten Bone Bolango Provinsi Gorontalo. Jenis penelitian ini menggunakan penelitian kualitatif deskriptif, dan teknik pengumpulan data menggunakan teknik observasi, wawancara, dan dokumentasi. Hasil penelitian menunjukkan bahwa sikap masyarakat terhadap pengembangan wisata pantai Botutonuo lorong 1cukup baik.Hal ini didasarkan pada sikap masyarakat terhadap fasilitas umum yang ada di wisata pantai botutonuo seperti adanya penginapan, warung makan, toilet/WC umum, mushala, pondok kayu, tempat parkir, dan adanya jasa perahu. Tersedianya fasilitas tersebut bisa menjadi nilai tersendiri bagi pengembangan wisata pantai Botutonuo.Selain itu, sikap masyarakat terhadap kebersihan objek wisata diketahui bahwa dari pihak pengelola selalu menjaga kebersihan lingkungan, dengan senantiasa membersihkan lingkungan pantai, area penginapan, pondok kayu serta menyediakan tempat sampah disekitar area pantai.

Kata Kunci: Sikap masyarakat, pengembangan wisata, pantai.

(C)2021 by Nurlayla Latif, Ummyssalam A.T.A Duludu Under the license CC BY-SA 4.0

\section{PENDAHULUAN}

Pariwisata merupakan salah satu pemanfaatan sumber daya alam yang dapat bernilai ekonomi tinggi bagi suatu daerah yang mengelola sumber daya alam menjadi suatu tempat wisata yang dapat menarik pengunjung baik dari dalam 
maupun dari luar negeri. Disamping bernilai ekonomi yang tinggi, pariwisata dapat menumbuhkan dan meningkatkan rasa bangga terhadap bangsa sehingga akan tumbuh masyarakat yang lebih peduli terhadap suatu bangsa. Pariwisata adalah hal yang diminati oleh setiap individu, karena dapat menghilangkan kejenuhan, berkembangnya kreativitas dan mampu menunjang produktivitas suatu individu.

Dasar hukum pengembangan pariwisata yang sesuai dengan prinsip pengembangan adalah Undang-Undang RI Nomor 10 Tahun 2009 tentang Kepariwisataan Pasal 6 menjelaskan bahwa pembangunan kepariwisataan dilakukan berdasarkan asas sebagaimana dimaksud dalam Pasal 2 yang diwujudkan melalui pelaksanaan rencana pembangunan kepariwisataan dengan memperhatikan keanekaragaman, keunikan, dan kekhasan budaya dan alam, serta kebutuhan manusia untuk berwisata). Pasal 8 ayat 1 menjelaskan bahwa pembangunan kepariwisataan dilakukan berdasarkan rencana induk pembangunan kepariwisataan yang terdiri atas rencana induk pembangunan kepariwisataan nasional, rencana induk pembangunan kepariwisataan provinsi, dan rencana induk pembangunan kepariwisataan kabupaten/kota. Pasal 8 ayat 2 menjelaskan bahwa Pembangunan kepariwisataan sebagaimana dimaksud pada ayat (1) merupakan bagian integral dari rencana pembangunan jangka panjang nasional. Pasal 11 menjelaskan bahwa Pemerintah bersama lembaga yang terkait dengan kepariwisataan menyelenggarakan penelitian dan pengembangan kepariwisataan untuk mendukung pembangunan kepariwisataan.

Dalam era globalisasi sekarang ini, bidang pariwisata merupakan salah satu kegiatan yang mempunyai peranan yang sangat strategis dalam menunjang pembangunan perekonomian nasional. Sektor ini dicanangkan selain sebagai salah satu sumber penghasildevisa yang cukup andal, juga merupakan sektor yang mampu menyerap tenaga kerja dan mendorong perkembangan investasi. Untuk mengembangkan sektor ini pemerintah berusaha keras membuat rencana dan berbagai kebijakan yang mendukung kearah kemajuan sektor ini. Salah satu kebijakan tersebut adalah menggali, menginventarisir dan mengembangkan obyek-obyek wisata yang ada sebagai daya tarik utama bagi wisatawan. 
Kabupaten Bone Bolango memiliki potensi disektor pariwisata. Adapun wisata yang terdapat di Kabupaten Bone Bolango adalah Olele Taman Bawah Laut, Pantai Botutonuo, Lombongo Wisata Alam, Air Terjun Lombongo, Danau Perintis, Air Terjun Molotabu Dan Panorama Pantai Molotabu, Air terjun Taludaa. Adapun yang menjadi ketertarikan dari peneliti adalah wisata Pantai Botutonuo.

Pantai Botutonuo adalah pantai yang terletak di desa Botutonuo, Kabupaten Bone bolango, Provinsi Gorontalo. Pantai ini merupakah salah satu objek wisata yang terdapat di Gorontalo. Pantai ini terletak dibalik rimbunnya pepohonan kelapa yang tumbuh memadati dataran sepanjang pantai sehingga tidak tampak dari jalan raya. Dari kota Gorontalo dibutuhkan waktu sekitar 25 menit ke lokasi ini. Untuk menuju ke lokasi pantai ada 10 lorong yang bisa dipilih disela-sela rumah-rumah warga. Panjang pantai yang bisa dijadikan tempat bersantai kurang lebih 1 kilometer. Permukaan Pantai Botutonuo memiliki ciri yang berdeda. Pada sisi arat bagian barat, pantai lebih berkarakteristik berpasir putih. Sementara pada sisi bagian daratan tengah dan timur, pantai lebih banyak berbatu-batu kerikil. Untuk mengunjungi pantai ini tidak dipungut biaya karena yang mengolola adalah warg setempat, hanya dikenakan biaya perkir kendaraan saja. Terdapat banyak deretan gubuk di tepian pantai yang bisa disewa untuk bersantai. Tarifnya cukup terjangkau. Untuk menikmati wisata air terdapat perahu nelayan yang bisa disewa untuk berkeliling seputaran area pantai.

Pariwisata dalam hal ini Botutonuo memerlukan usaha pengembangan secara terus menerus. Dengan adanya pengembangan Botutonuo diharapkan mampu memberikan daya saing terhadap daerah tujuan wisata lain, baik dari segi pelayanan, maupun objek wisata dan lain sebagainya sehingga dapat menyesuaikan dengan selera wisatawan. Kegiatan pengembangan usaha wisata pantai tentu tidak lepas dari keadaan sosial, ekonomi dan lingkungan.

Sikap adalah suatu pikiran, kecenderungan dan perasaan seseorang untuk mengenal aspek-aspek tertentu pada lingkungan yang sefringnya bersifat permanen karena sulit diubah. Sikap juga merupakan keccondongan evaluatif 
seseorang terhadap suatu subjek atau objek. Sikap yang dimiliki setiap individu memberikan warna tersendiri untuk seseorang bertingkah laku.

Masalah yang terdapat di Pantai Botutonuo ini yaitu banyaknya sampah yang berserakan di sekitar pantai tersebut, sehingga dapat mengganggu masyarakat atau pengunjung yang sedang menikmati liburan mereka di pantai Botutonuo.Adanya kecenderungan masyarakat membuang sampah sembarangan mengakibatkan kerusakan lingkungan pantai Botutonuo. Adanya sikap masyarakat yang yang kurang peduli terhadap lingkungan akan berakibat pada proses pengembangan wisata pantai Botutonuo.

Dampak atau efek yang ditimbulkan dalam pengembangan objek Wisata Pantai Botutonuo ini, kurangnya partisipasi masyarakat untuk menjaga sekitaran lingkugan. Akibat dari kurangnya partisipasi tersebut, pengunjung atau wisatawan yang ingin berkunjung di pantai itu merasa terganggu dengan masalah. Salah satunya yaitu tentang sampah. Dampak lainnya yaitu kurangnya kesadaran masyarakat terhadap kesadaran kebersihan, kurangnya motivasi terhadap pengembangan wisata pantai, kurangnya ilmu pengetahuan tentang pemanfaatan tempat wisata.

Usaha yang harus dilakukan masyarakat yaitu, masyarakat harus lebih memperhatikan kondisi sekitaran pantai tersebut, agar pengunjung atau wisatawan yang ingin mengunjungi Pantai Botutonuo tidak terganggu dengan adanya masalah sampah yang dapat mengganggu liburan para pengunjung. Usaha lain yang harus dilakukan adalah perlu memberikan penyuluhan pada masyarakat dan mengundang para ahli dari dinas kesehatan, dinas pariwisata untuk memberikan penyuluhan kepada masyarakat terhadap wisata tersebut, agar wisata pantai Botutonuo terlihat bersih, indah dan menarik wisatawan yang datang ke pantai Botutonuo.

Beberapa upaya yang dapat dilakukan untuk meningkatkan sektor kepariwisataan antara lain:

Meningkatkan kuantitas dan kualitas fasilitas di objek wisata, Menjaga keasrian dan kelestarian objek wisata, Menjaga keamanan dan kenyamanan objek wisata. Agar para wisatawan merasa betah dan aman, Meningkatkan sarana dan 
pra sarana transportasi, Memasyarakatkan program sapta pesona pariwisata yaitu aman, tertib, bersih, sejuk, indah, dan kesan baik yang berhubungan dengan kesan tentang berbagai hal yang terdapat di objek wisata.

Kondisi/Masalah yang ada di Pantai Botutonuo yaitu pengunjung harus berhati-hati, sebab jalurnya berkelok-kelok, menurun, meninggi, dan jalur yang berada ditepian pesisir serta tebing-tebing karang. Kondisi geografis menuju Pantai Botutonuo sangat panas, tetapi bila di malam hari hawa dingin terasa karena hembusan angin Pantai.

Berdasarkan hasil observasi, di Pantai Botutonuo di kabupaten Bone Bolango, sebagian besar pengunjung yang mendatangi pantai itu ada yang terganggu terhadap masalah sampah yang berserakan di sekitar Pantai tersebut.

Adapun hasil wawancara peneliti dengan sebagian masyarakat yang tinggal di sekitar wisata pantai botutonuo pada tanggal 17 Oktober 2019 "tidak heran banyak yang mengunjungi Pantai Botutonuo di saat hari libur atau hari-hari lainnya, karena Pantai Botutonuo ini dilengkapi berbagai fasilitas pendukung seperti: pondok kayu tempat bersantai di pesisir pantai. Adapun yang menjadi masalah di pantai yaitu banyaknya sampah yang berserakan di pesisir/sekitar pantai. Selain itu, masih perlunya pembenahan terhadap fasilitas yangada untuk pengembangan objek Wisata Pantai Botutonuo.

Konsekuensi jika masalah ini diabaikan, pengunjung akan semakin banyak merasa terganggu dengan adanya sampah yang berserakan disekitaran pantai, sehingga mengurangi nilai dan daya tarik bagi pengunjung. Kurangnya kesadaran masyarakat akan pentingnya menjaga kebersihan lingkungan pantai mengakibatkan kerusakan lingkungan pantai itu sendiri.

\section{METODE}

Jenis penelitian yang peneliti lakukan adalah penelitian kualitatif, maka penelitian ini dimaksudkan untuk menggali suatu fakta, yang digunakan peneliti adalah penelitian kualitatif. Bogdan dan Taylor mendefinisikan penelitian kualitatif yaitu sebagai prosedur penelitian yang menghasilkan data deskriptif berupa kata-kata tertulis atau lisan dari orang-orang dan pelaku yang diamati 
(Moleong, 2005:4). Lalu memberikan penjelasan terkait berbagai realita yang ditemukan.

Berdasarkan pada pandangan di atas, maka penelitian kualitatif dalam penelitian ini dimaksudkan untuk menggali suatu fakta, lalu memberikan penjelasan terkait berbagai realita yang ditemukan. Olehnya itu, peneliti langsung mengamati peristiwa-peristiwa di lapangan yang berhubungan dengan Sikap Masyarakat Terhadap Pengembangan Wisata Pantai Botutonuo.

Data yang dibutuhkan dalam penelitian ini secara umum terdiri dari data yang bersumber dari penelitian lapangan. Sehubungan dengan penelitian ini, maka pengumpulan data yang dilakukan oleh penulis melalui observasi, wawancara dengan mengajukan beberapa pertanyaan penelitian dan dokumentasi.

\section{HASIL DAN PEMBAHASAN}

\section{Hasil}

Hasil penelitian menunjukkan bahwa sikap Masyarakat terhadap fasilitas umum wisata yang terdiri dari ketersediaan penginapan, warung makan, toilet/WC umum, mushala, pondok, parkir dan perahu. Berdasarkan hasil observasi bahwa di lorong 1 wisata pantai Botutonuo terdapat penginapan bagi para pengunjung atau wisatawan. Penginapan di wisata pantai Botutonuo memiliki fasilitas yang aman, terjamin, dan lengkap (terdapat WC dan Televisi). Selain itu, penginapan ini berukuran besar dan luas, sehingga pengunjung yang menginap dengan jumlah 5 orang bisa leluasa dan nyaman berada di penginapan. Dan tak kalah penting di lengkapi pula dengan CCTV di halaman penginapan agar bisa mengontrol segala aktivitas di luar penginapan. Sehingga hal-hal yang mencurigakan maupun memahayakan bisa segera diatasi dengan adanya kamera pengintai yaitu CCTV.

Keberadaan wisata pantai Botutonuo ini, telah banyak menarik perhatian masyarakat baik yang ada di lingkungan wisata pantai Botutonuo maupun yang berada di luar lingkungan wisata tersebut. hal ini dbuktikan dengan ramainya pengunjung wisata di setiap akhir pekan. Salah satu cara menarik orang untuk berkunjung ke tempat wisata Botutonuo ini bisa dilakukan dengan berbagai cara salah satunya dengan melalui media sosial baik facebook, instagram, whatsapp, 
dan juga youtube. Karena mengingat zaman sekarang ini, informasi yang disajikan begitu cepat melalui media sosial yang ada. Selain melalui media sosial, daya tarik tersendiri untuk masuk ke pantai Botutonuo ini adalah tidak dikenakan tarif khusus untuk masuk, hanya saja membayar parkir maupun pondok kayu yang digunakan. Hal ini menjadi salah satu nilai tersendiri untuk setiap pengunjung wisata pantai Botutonuo.

Salah satu aspek yang tak kalah penting adalah menjaga kebersihan objek wisata Botutonuo. Untuk menjaga kebersihan lingkungan pantai Botutonuo, pengelola sudah menyiapkan tempat sampah disekitar area pantai. Dari pengelola pantai Botutonuo itu sendiri, sudah berupaya membersihkan lingkungan pantai, pondok kayu, WC/toilet umum dan juga area penginapan setiap hari. Namun, kebanyakan para wisatawan masih saja membuang sampah sembarang walaupun sudah disediakan tempat sampah disekitar area pantai Botutonuo. Kebanyakan para wisatawan yang berkunjung selalu meninggalkan berbagai macam sampah disekitar pantai ataupun pondok kayu tempat mereka bersantai.

Akses jalan menuju wisata pantai Botutonuo sudah terbilang baik. Namun, pada saat hujan di sekitar area parkir sering terjadi becek sehingga menyulitkan wisatawan yang berjalan kaki karena terhalang dengan becek yang ada. Untuk akses jalan dari arah timur pantai, pengunjung harus berhati-hati, sebab jalurnyaberkelok-kelok, menurun, meninggi, dan jalur yang berada ditepian pesisir serta tebing-tebing karang. Sehingga hal ini cukup menyulitkan bagi pengunjung yang baru pertama kali berwisata di pantai Botutonuo.

\section{Pembahasan}

Sikap masyarakat sejak adanya wisata pantai Botutonuo hingga sekarang ini terbilang sangat baik, sopan dan juga ramah. Jika ada wisatawan yang membutuhkan sesuatu, selalu mereka bantu tanpa pamrih. Sikap masyarakat. Sangat membantu jika ada wisatawan yang tersesat di lorong ataupun sekitar pantai. Sikap keramahtamahan ini menjadi salah satu daya tarik tersendiri bagi masyarakat maupun pengunjung wisata pantai Botutonuo. 
Sikap masyarakat terhadap kondisi keamanan; menjaga ketertiban dan kemanana tempat wisata dimana pihak pengelola wisata Botutonuo selalu menjaga ketertiban dan keamanan dengan cara melarang para pengunjung membawa minuman keras di area pantai guna menghindari hal-hal yang tidak diinginkan. Pengelola juga tidak menyediakan minuman keras bagi pengunjung agar tetap menjaga keamanan dan ketertiban lingkungan pantai Botutonuo. Jika hanya sekedar karaoke dan lain sebagainya akan diijinkan oleh pihak pengelola wisata pantai Botutonuo.

Selain adanya penginapan, terdapat pula warung makan disekitaran pantai Botutonuo. Menu yang disediakan bermacam-macam, mulai dari makanan berat seperti nasi, lauknya seperti cumi, ikan bakar, dan berbagai olahan ikan lainnya. Disediakan pula berbagai macam mie instan mulai dari mie kuah maupun goreng. Sedangkan untuk makanan ringan disediakan snack yang bermacam-macam. Keberadaan wisata pantai Botutonuo ini bisa meningkatkan ekonomi masyarakat yang ada disekitar pantai Botutonuo dengan berjualan.

Keberadaan penginapan dan juga warung makan tak lengkap bila tanpa adanya WC/toilet umum. Diketahui bahwa wisatawan yang akan menggunakan WC/toilet umum akan dikenakan tarifdua ribu rupiah per orang. Jelas harga ini terjangkau untuk semua wisatawan. Begitupun penginapan, dilengkapi dengan fasilitas toilet yang dilengkapi dengan shower didalamnya. Selain adanya WC/toilet umum, wisata ini pula dilengkapi dengan mushala yang belum lama ini dibangun oleh pengelola wisata pantai Botutonuo. Pada setiap lorong pantai Botutonuo terdapat parkir untuk kendaraan roda dua maupun empat yang dikenakan tarif parkir khususnya motor Rp. 2.000, sedangkan untuk mobil Rp. 5.000 .

Fasilitas umum yang tak kalah penting adalah adanya pondok kayu. Pondok kayu ini digunakan wisatawan untuk duduk bersantai bersama keluarga maupun sanak saudara. Pondok kayu dibangun dengan jumlah yang banyak disetiap lorong pantai Botutonuo dengan tarif yang telah ditetapkan dengan jumlah wisatawan yang tidak dibatasi untuk duduk di pondok kayu tersebut. Adanya pondok kayu 
ini guna memberikan kenyamanan serta melindungi dari terik sinar matahari dan juga hujan bagi wisatawan yang ingin menikmati suasana pantai Botutonuo.

Selain pondok kayu, yang tak kalah penting lainnya adalah keeradaan perahu bagi masyarakat yang ingin menikmati panorama pantai Botutonuo secara keseluruhan. Untuk tarif naik perahu ini per orang Rp. 5.000. Jadi, untuk wisatawan yang ingin naik perahu bisa menikmati suasana pantai dengan diajak berkeliling area pantai sambil mendengarkan musik yang diputar oleh pengemudi perahu. Keberadaan fasilitas umum di pantai Botutonuo ini, dapat menjadikan wisata pantai Botutonuo semakin berkembang kedepannya dan bisa menunjang keberadaan wisata pantai Botutonuo.

\section{SIMPULAN}

Berdasarkan hasil penelitian dan pembahasan pada bab sebelumnya, maka peneliti dapat menyimpulkan bahwa sikap masyarakat terhadap pengembangan wisata pantai botutonuo lorong 1 cukup baik.Hal ini terlihat dari sikap masyarakat terhadap fasilitas umum wisata yang sudah memadai, sikap ramah masyarakat kepada wisatawan, sikap masyarakat terhadap ketertiban dan keamanan yang sudah baik diantaranya dengan senantiasa menaati peraturan yang ditetapkan pengelola wisata Botutonuo, dan kualitas lingkungan alam yang cukup baik. Sikap masyarakat terhadap kebersihan objek wisata masih kurang. Hal ini terlihat dari masih adanya kecenderungan masyarakat maupun wisatawan yang membuang sampah sembarangan. Walaupun pihak pengelola sudah menyediakan tempat sampah disekitar area pantai.

Kurangnya kesadaran masyarakat akan pentingnya menjaga kebersihan lingkungan pantai mengakibatkan kerusakan lingkungan pantai itu sendiri. Adanya sikap masyarakat yang kurang peduli terhadap lingkungan akan berakibat pada proses pengembangan wisata pantai Botutonuo 


\section{DAFTAR PUSTAKA}

Arifin. 2011. Metode Penelitian Kuantitatif, Kualitatif Dan R\&D. Bandung Alfabeta

Azwar, Saifudin. 2012. Sikap Manusia: Teori dan Pengukurannya. Yogyakarta: Pustaka Pelajar

Bafadhal, Aniesa. 2018. Perencanaan Bisnis Pariwisata(Pendekatan Learn Planning). Malang: UB Press

Keputusan Menteri Pariwisata, Pos Dan Telekomunikasi No. KN.73/PVVI05/MPPT-85 Tentang Peraturan Usaha Rumah Makan

Kurniawan. 2015. Pengaruh Kepuasan Kerja, Motivasi Kerja, Dan Kedisiplinan Terhadap Kinerja Karyawan PT. Garam (PERSERO)

Kaiser, Charles Jr. dan Larry E. Helber. 1978. Tourism Planning And Development

Sinaga. 2010. Potensi Dan Pengembangan Objek Wisata Di Tapanuli Tengah. Universitas Sumatera Utara. Sumatera Utara 